\title{
SOBRE UNAS IMITACIONES DEL DENARIO RRC 443/1 DE C. JULIO CÉSAR A NOMBRE DE A. HIRCIO Y C. CARRINAS ${ }^{1}$
}

\author{
ON SOME IMITATIONS OF DENARIUS \\ RRC 443/1 of C. JULIUS CAESAR \\ ON BEHALF OF A. HIRITIUS AND C. CARRINAS
}

LUIS AMELA VALVERDE

Universidad de Barcelona ${ }^{2}$

\begin{abstract}
Resumen: El presente artículo trata acerca de las imitaciones en bronce del denario RRC 443/1, conocido como el "denario del elefante", de C. Julio César (cos. I 59 a.C.), efectuadas en el oppidum trevero de Titelberg a finales de la República romana, y que presumiblemente sirvieron para pagar las soldadas de los auxiliares galos.

Palabras clave: Imitaciones, Amonedación galorromana, Titelberg, Soldada.
\end{abstract}

\begin{abstract}
This article is about the imitations in bronze of the denarius RRC 443/1, known as the "Caesar's Elephant", of C. Julius Caesar (cos. I $59 \mathrm{BC}$ ), made in the treverian oppidum Titelberg of the late Roman Republic, and presumably used to pay the Gallic auxiliaries.

Keywords: Imitations, Gallo-Roman coinage, Titelberg, Pay.
\end{abstract}

\footnotetext{
${ }^{1}$ Abreviaturas utilizadas en este trabajo: BN: E. MURET Y A. CHABOUILLET, Catalogue des monnaies gauloises de la Bibliothèque Nationale, Paris, 1889. CNH: L. VILLARONGA, Corpvs Nvmmorvm Hispaniae ante Avgvsti Aetate, Madrid, 1994. Depeyrot: G. DEPEYROT, Le numéraire celtique VII. La Gaule orientale, Wetteren, 2005. DT: L.-P. DELESTRÉE Y M. TACHE, Nouvel Atlas des Monnaies Gauloises, I. De la Seine au Rhin, Saint-Germain-en Laye, 2002. LT: H. de la Tour, Atlas de monnaies gauloises, Paris, 1892. A. M. BURNETT, M. AMANDRY Y P. P. RIPOLLĖS, Roman Provincial Coinage. Volume I. From the Death of Caesar to the Death of Vitellius (44 BC-AD 69). Part I: Introduction and Catalogue. Part II: Indexes and Plates, Paris, 1992. RRC: M. H. CRAWFORD, Roman Republic Coinage. 2 vols., Cambridge, 1974. Scheers: S. SCHEERS, Les monnaies de la Gaule inspirées de celles de la République romaine, Paris, 1969. Sear: R. S. SEAR, The History and Coinage of Roman Imperators, 49-27 BC, London, 1998.

${ }^{2}$ Grupo CEIPAC. Este trabajo se ha realizado en el marco del Proyecto I+D+I2009-2011 HAR2008-00210.
} 


\section{INTRODUCCIÓN}

El presente artículo pretende actualizar parte de un trabajo que publicamos sobre el denario RRC 443/1, de C. Julio César (cos. I 59 a.C.), emitido en los años 49-48 a.C., y sus diversas imitaciones ${ }^{3}$. Consideramos de interés profundizar en estas últimas monedas, más concretamente las que mencionan a dos gobernadores de la provincia de la Galia Comata, acuñadas en el oppidum trevero de Titelberg (Luxemburgo), en la Gallia Belgica ${ }^{4}$, con letreros latinos, por lo que se trata de amonedaciones galorromanas.

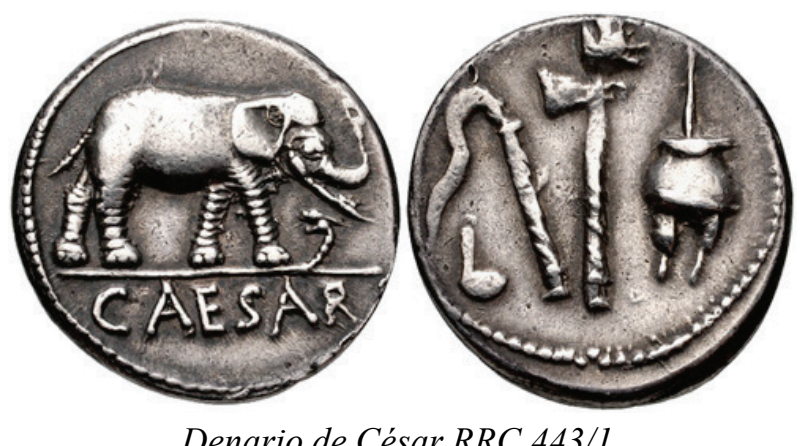

La primera imitación (y la más conocida de ellas) que tratamos es una moneda a nombre de A. Hircio (pr. 46 a.C., cos. 43 a.C.) (BN 9233-9244. DT 612. LT 9235. RPC 501. Depeyrot, VII, 102. Scheers 162 clase I. Sear 473) ${ }^{5}$, de 16/17 $\mathrm{mm}$. de diámetro y un peso medio de 2.69 g. (418 ejemplares $)^{6}$, con oscilación

${ }^{3}$ L. AMELA VALVERDE, "La emisión cesariana RRC 443/1 y sus imitaciones", Numisma 246, (2002), 7-37. Dos adicciones: L. AMELA VALVERDE, "Nueva(s) variante(s) de RRC 443/1 (denario de César con elefante)", GN 180 (2011), 3-8; "Una imitación gala del denario de César con elefante (RRC 443/1). Una nota”, en Varia nummorum (Barcelona, 2012), 59-61.

${ }^{4}$ Sobre la problemática de la historia de las acuñaciones belgas, vid: L.-P. DELESTRÉE, "La numismatique gauloise en Gaule Belgique. Problématique et axes de recerche", $R N, 36$ (1994), 725.

5 J.-B. COLBERT DE BEAULIEU, Traité de numismatique celtique, I. Méthodologie des ensembles, Paris, 1973, p. 330 menciona el hallazgo de un denario forrado a nombre de Hircio, cuyo reverso es del tipo BN 9235, que atribuye (erróneamente) a los Remi, e indica que ni Muret y Chabouillet, ni La Tour ni Blanchet señalaron la existencia de monedas de plata a nombre de Hircio imitando al denario RRC 443/1 de César. Este dato es muy interesante, ya que indica que las monedas de César circulaban por la Galia por lo que eran objeto de los falsarios, que crearon una pieza original, a la que cambiaron el nombre de César por el de Hircio, por lo que es también indicativo de que los bronces de este último eran conocidos.

${ }^{6}$ R. WEILLER, "Les techniques de fabrication employées dans l'atelier monétaire de l'oppidum trévire deTetelbierg (Gran-Duché de Luxembourg)", en Actes du 9eme Congrès International de Numismatique, I. Numismatique antique, Louvain-la-Neuve, 1982, 625-632, p. 626. A. M. BURNETT, M. AMANDRY y P. P. RIPOLLÈS, Roman Provincial Coinage..., p. 148. R. PRO- 
entre 1.70 a 3.70 g. $^{7}$ La fabricación ${ }^{8}$ es de peor calidad que la de los denarios RRC $443 / 1^{9}$ de César y, evidentemente, una imitación de éstos ${ }^{10}$. La descripción es la siguiente:

BST, Catalogue illustré des monnaies trévires, Luxembourg, 1997, p. 78 señala un peso (medio) de $4,11 \mathrm{~g}$, ciertamente sorprendente.

${ }^{7}$ S. SCHEERS, Traité de numismatique celtique, II. La Gaule Belgique, Paris, 1977, p. 208. S. SCHEERS, Les monnaies de la Gaule..., p. 71 daba 2.05 a 3.48 g., mientras que G. DEPEYROT, Le numéraire celtique VII..., p. 193 da ca. 3,00 g. H. A. GRUEBER, Coins of the Roman Republic in the British Museum. Vol. I. Aes rude, aes signatum, aes grave, and coinage of Rome from B.C. 268, London, 1910, p. 526 indica que estamos frente a una metrología gala. El hecho de que pudiera tratarse de un quadrans lo rechaza Grueber al señalar que esta fracción no era acuñada en esta época en la ceca de Roma.

${ }^{8}$ S. SCHEERS, Traité de numismatique celtique..., p. 152 indica que si bien la presente emisión es obra de artistas galos, la imitación del denario de César y la presencia del nombre de Hircio indican que esta emisión fue efectuada por este último. 190.

${ }^{9}$ S. SCHEERS, Les monnaies de la Gaule..., p. 71; Traité de numismatique celtique..., p.

${ }^{10}$ E. BABELON, Description historique et chronologique des monnaies de la République romaine, Paris, 1886, p. 541. A. BLANCHET, Manuel de numismatique française, Tome premier, Paris, 1905, p. 384. H. A. GRUEBER, Coins of the Roman Republic..., p. 526. V. TOURNEUR, "César, Hirtius et un bronze des Trévires", $A C, 17$ (1948), 553-558, p. 556. S. SCHEERS, Les monnaies de la Gaule..., pp. 71 y 169-171; Traité de numismatique celtique..., pp. 152, 188 у 666; "Le Tetelbierg et la circulation monétaire sur le territoire des Treviri", en Studien zu Fundmünzen der Antike, I, Berlin, 1979, 225-239, p. 227; S. "Géographie et chronologie des monnaies de la Gaule imitées des monnaies romaines", en Die Kelten und Rom: Neue numismatische Forschungen - Les Celtes et Rome: Nouvelles etudes numismatiques, Mainz am Rhein, 2005, 71-85, p. 76. E. M. WIGHTMAN, "Military arrangements, native settlements and related developments in Early Roman Gaul", Helinium 17 (1977), 105-126, p. 120. Probst, Catalogue illustré..., p. 79. L. REDING, "Die Treverermünzen im Raum Luxemburg - Trier (Versuch einer chronologischen Eingliederung", en Keltische Numismatik und Archaeologie, Part II = Numismatique celtique et Archéologie, Part II, Oxford, 1984, 319-338, p. 323. M. H. CRAWFORD, Coinage \& Money under the Roman Republic, Italy \& the Mediterranean Economy, London, 1985, p. 218. K. GRUEL, La monnaie chez les gaulois, Paris, 1989, p. 79. A. M. BURNETT, M. AMANDRY y P. P. RIPOLLÈS, Roman Provincial Coinage..., p. 148. M. MAYS, Catalogue of the Celtic Coins in the British Museum, with supplementary material from other British collections. Volume III. Bronze Coins of Gaul, London, 1995, pp. 37 y 66. T. LEIDIG, "C. CARRINAS C.F. Überlegungen zu zewi Bronzenmünzen der Treverer", ZPE, 122 (1998), 211-218, p. 212. C. HASELGROVE, "The Development of Iron Age Coinage in Belgic Gaul", NC, 159 (1999), 111-168, p. 152. SEAR, The History and Coinage..., p. 271. D. G. WIGG, "The development of the monetary economy in N. Gaul in the late La Tène and early Roman periods", en Roman Germany. Studies in Cultural Interaction, Portsmouth, 1999, 99-124, p. 108. L.-P. DELESTRÉE y M. TACHE, Nouvel Atlas..., p. 120. S. GOUET, M. PRIEUR Y L. SCHMITT, Monnaies XV, Paris, 2002, pp. 387-388 y 430. B. WOYTEK, Arma et Nummi. Forschungen zur römischen Finanzgeschichte und Münzprägung der Jahre 49 bis 42 v. Chr., Wien, 2003, p. 123. L.-P. DELESTRÉE, "La romanisation et la fin du monnayage celtique dans le nord de la Gaule", en Die Kelten und Rom: Neue numismatische Forschungen - Les Celtes et Rome: Nouvelles etudes numismatiques, Mainz am Rhein, 2005, 129145, p. 133. R. H. M. LOSCHEIDER, "Militär und Romanisierung: zum Münzwesen der Treverer nach dem Gallischen Krieg", en Die Kelten und Rom: Neue numismatische Forschungen - Les Celtes et Rome: Nouvelles etudes numismatiques, Mainz am Rhein, 2005, 109-127, p. 112, quien señala en 113 que los bronzes treveros posteriores a la Guerra de las Galias copian parte o toda su 

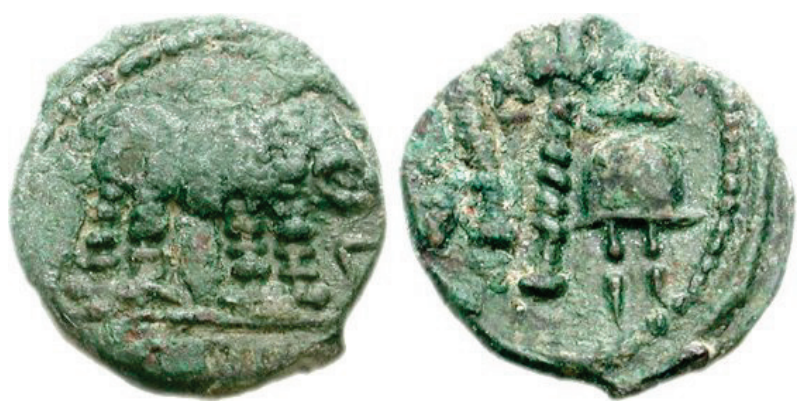

Anv.: Elefante ${ }^{11}$ a der. ${ }^{12}$, sobre la línea de exergo ${ }^{13}$; debajo, leyenda A. HIRTIVS $^{14}$ (en lugar de CAESAR del denario RRC 443/1) ${ }^{15}$.

Rev.: Culullus, aspergillum, securis y apex.

No existen problemas en cuanto a su atribución, pues estas piezas fueron emitidas en el territorio de la etnia de los Treveri $^{16}$ (otros investigadores las atri-

iconografía de modelos romanos, siendo las monedas a nombre de HIRTIVS y CARRINAS las que siguen en todo el original romano. Incomprensiblemente, G. RÜGER, "Germany", en The Cambridge Ancient History. Volume X. The Augustan Empire, 43 B.C.-A.D. 69, Cambridge, 1996, 517-534, pp. 522-523 señala que la tipología del anverso reflejaría la utilización de elefantes por parte de Cn. Domicio Enobarbo (cos. 122 a.C.) de elefantes contra los Alóbroges en el año 121 a.C. (Flor. 1, 37, 4. Oros. 5, 13, 2. Suet. Nero 2), que vio el final del despliegue táctico de elefantes en el continente europeo.

${ }^{11}$ La figuración del elefante parece representar al propio César pero, debido a que no existe actualmente consenso en explicar la presencia en el denario RRC 443/1 de la serpiente frente al paquidermo, es difícil conocer su significado concreto.

${ }^{12}$ R. PROBST, Catalogue illustré..., p. 78 señala la existencia de una variante con el elefante ubicado hacia la izquierda en vez de hacia la derecha, y en p. 79 de otra variante en que la cola está realizada mediante puntos finos.

${ }^{13}$ Algunos ejemplares dejan entrever la serpiente o el dragón del prototipo romano. M. GREEN, "The iconography of Celtic coins", en Celtic Coinage: Britain and Beyond. The Eleventh Oxford Symposium on Coinage and Monetary History, Oxford, 1992, 151-163, p. 160 explica la importancia de las serpientes en la moneda celta.

${ }^{14}$ BN 9243-9244 presentan en lugar del letrero A. HIRTIVS la inscripción retrógrada VITRIHA. Probst, Catalogue illustré..., pp. 78-79 ofrece el siguiente listado de variantes de la presente leyenda, que este investigador reproduce como A HIRTIVS: A HIRTIV, VITRIHA (letrero retrógrado), SVITRIHA (letrero retrógrado), VIT $\Lambda$ II, VIT今III, SVIT今IH A, VIT ЯIII $\Lambda, \Lambda \Lambda$ VIISIT २, $\Lambda \cdot \cdot$ II $९$ TIVS, HIIT $\Lambda$ II, AHITI.

${ }^{15}$ En la foto no se aprecia claramente el letrero.

${ }^{16}$ F. DE SAULCY, Système monétaire de la République Romaine à l'époque de Jules César, Paris, 1873, p. 4. BABELON, Description historique..., pp. 11, 540-541 y 543. E. MURET y C. CHABOUILLET, Catalogue des monnaies..., p. 213. A. BLANCHET, Traité des monnaies..., p. 383; Manuel de numismatique française. Tome premier. Monnaies frappées en Gaule depuis les origins jusqu'a Hugues Capet, Paris, 1912, p. 59. V. TOURNEUR, "La Belgique pendant l'occupation militaire romaine. 49-27 avant J.-C.", Latomus, 5 (1946), 175-180, p. 180; “César, Hirtius...”, p. 555. P.-C. VIAN, "La trouvaille d'Husigny-Godbrange”, Ogam 6 (1954), 195-198, p. 195. M. GRANT, From Imperium to Auctoritas. A Historical Study of Aes Coinage in the Roman Empire 49 B.C.-A.D. 14, Cambridge, $1969^{2}$, pp. 3-4. S. SCHEERS, Les monnaies de la Gaule..., p. 171; Traité de numismatique celtique..., pp. 152 y 190-191; "Géographie et chronologie 
buyeron, erróneamente, a los $L e u c i^{17}$ o a los $\operatorname{Remi}^{18}$. El mapa de hallazgos muestra su distribución en el área NE de la Galia, especialmente entre los Remi y los Treviri $\left.^{19}\right)$. Con total seguridad la ceca estuvo instalada en el oppidum de Titelberg $^{20}$ (o Tëtelbierg) ${ }^{21}$, la capital de los Treveros durante la primera fase de ocupación romana, donde se han encontrado 710 ejemplares $^{22}$.

des monnaies...”, p. 76. H. ZEHNACKER, Moneta. Recherches sur l'organisation et l'art des émisions monétaires de la République romaine (289-31 avant J.-C.). 2 vols., Rome, 1973, p. 918. E. M. WIGHTMAN, "Military arrangements...", p. 120. R. WEILLER, "Les techniques de fabrication...", p. 626. L. REDING, "Die Treverermünzen im Raum...", p. 323. M. H. CRAWFORD, Coinage \& Money under the Roman Republic..., p. 218. GRUEL, La monnaie chez les gaulois, p. 79. A. M. BURNETT, M. AMANDRY y P. P. RIPOLLĖS, Roman Provincial Coinage..., pp. 147148. MAYS, Catalogue of the Celtic Coins..., pp. 37 y 66. J. METZLER, Das Treverische Oppidum auf dem Titelberg, G.-H. Luxembourg. Zur Kontinuität zwischen der späkeltischen und der frühromaichen Zeit in Nord-Gallien, Luxembourg, 1995, p. 129. T. LEIDIG, "C. CARRINAS C.F....", p. 214. L.-P. DELESTRÉE, "La romanisation et la fin du monnayage celtique dans le Nord de la Gaule", $R N 154$ (1999), 15-40, p. 29; "La romanisation et la fin du monnayage..", p. 135. L.-P. DELESTRÉE y M. TACHE, Nouvel Atlas..., pp. 120 y 132. B. WOYTEK, Arma et Nummi..., p. 123. G. DEPEYROT, Le numéraire celtique VII..., p. 141. C. HASELGROVE, "The incidence of Iron Age coins on archaeological sites in Belgic Gaul", en Die Kelten und Rom: Neue numismatische Forschungen - Les Celtes et Rome: Nouvelles etudes numismatiques, Mainz am Rhein, 2005, 247-296, p. 289. R. H. M. LOSCHEIDER, "Militär und Romanisierung...", p. 109. J. VAN HEESCH, "Les Romains et la monnaies gauloise: laissr-faire, laisser-aller?", en Die Kelten und Rom: Neue numismatische Forschungen - Les Celtes et Rome: Nouvelles etudes numismatiques, Mainz am Rhein, 2005, 229-245, p. 240. F. REINERT, "La numismatique celtique au Luxembourg. Une réactualisation après 30 ans de fouilles et prospections archéologiques", en Coinage in the Iron Age. Essays in honour of Simone Scheers, London, 2009, 337-361, p. 338. S. GOUET ET ALII, Celtic I, Paris, 2010, p. 195. A. BLANCHET, Traité des monnaies..., p. 384 indica que en la zona se habían encontrado denarios de César RRC 443/1, es decir, con los mismos motivos de la moneda de Hircio.

${ }^{17}$ L. MAXE-WERLY, "État actuel de la numismatique rémoire", RBN, 44 (1888), 433-440, pp. 434-435.

${ }^{18}$ A. BLANCHET, Traité des monnaies..., p. 383.

${ }^{19}$ S. SCHEERS, Les monnaies de la Gaule..., pp. 168 y 170-171; Traité de numismatique celtique..., pp. 666-668.

${ }^{20}$ El importante oppidum de Titelberg se encuentra al SO. de Luxemburgo, y está considerado como la localidad principal de los Treveros antes de la fundación de la ciudad romana de $A u$ gusta Treverorum (act. Treveris). Se encuentra en la ruta principal que cruza por el Oeste el territorio trevero, y continuó siendo el centro de esta etnia al menos durante otros veinte años después de la conquista de las Galias; siguió floreciendo en tiempos de Augusto. Se desconoce qué papel pudo jugar en la revuelta trevera del año 29 a.C., vid infra.

${ }_{21}$ S. SCHEERS, Traité de numismatique celtique..., p. 152; "Le Tetelbierg et la circulation monétaire...", p. 227. E. M. WIGHTMAN, "Military arrangements...", p. 120. GRUEL, La monnaie chez les gaulois, p. 79. A. M. BURNETT, M. AMANDRY y P. P. RIPOLLÈS, Roman Provincial Coinage..., p. 148. MAYS, Catalogue of the Celtic Coins..., pp. 37 y 76. J. METZLER, Das Treverische Oppidum..., p. 159. C. BRENOT Y S. SCHEERS, Catalogue des monnaies massaliètes et monnaies celtiques du Musée des Beaux-Arts de Lyon, Leuven, 1996, p. 140. PROBST, Catalogue illustré..., p. 78. SEAR, The History and Coinage..., p. 271. C. HASELGROVE, "The Development of Iron Age Coinage...”, p. 160. WOYTEK, Arma et Nummi..., p. 123. J. VAN HEESCH, "Les Romains et la monnaies gauloise...", p. 240. R. H. M. LOSCHEIDER, "Militär 


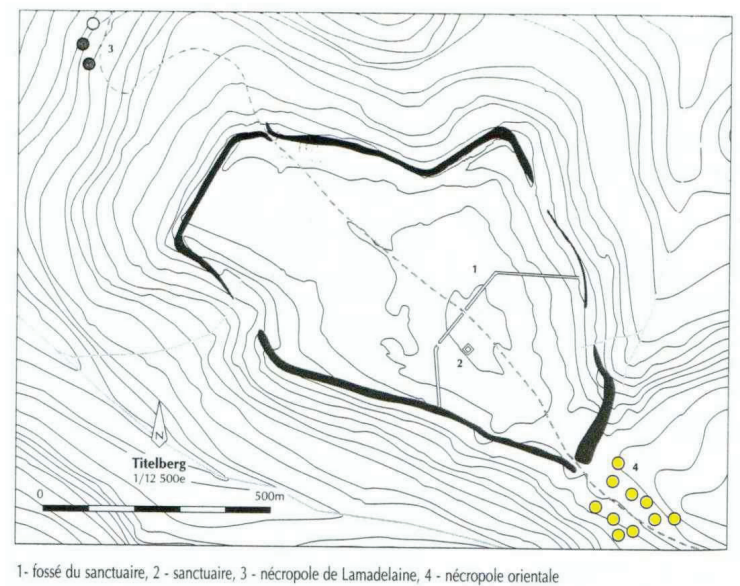

Plano de Titelberg.

Esta emisión tuvo a su vez una imitación propiamente gala, un potin ${ }^{23}$, anepigráfico (BN 8351-8359. DT 221. LT 8351), cuya circulación se extendió por el norte de la Galia, en cuyo reverso se efectúa una interpretación indígena del elefante $^{24}$. Se ha atribuido su fabricación a los Catalaunes o a los Lingones ${ }^{25}$ pero, en realidad, su acuñación ha de atribuirse a los $R e m i^{26}$.

und Romanisierung...”, p. 113. Que ciertamente hubo un taller monetario en Titelberg lo demuestra que en el año 2003, en la tumba 167, situada en la necrópolis oriental, se encontrara un punzón del reverso de una moneda de tipo ARDA (DT 155. LT 8852), como indica REINERT, "La numismatique celtique au Luxembourg...", p. 339. V. TOURNEUR, "La Belgique pendant l'occupation militaire romaine...", p. 180 señaló que la ceca de esta emisión se encontraba en $A u$ gusta Treverorum, seguramente por considerar a esta ciudad el centro de la etnia trevera.

${ }^{22}$ S. SCHEERS, "L'histoire monétaire de la Gaule Belgique après la conquête de César", en Actes du 8eme Congrès International de Numismatique, Paris, 1976, 197-201, p. 198. A. M. BURNETT, A. AMANDRY y P. P. RIPOLlÈS, Roman Provincial Coinage..., p. 147-148. M. MAYS, Catalogue of the Celtic Coins..., pp. 37 y 66. S. GOUET, M. PRIEUR y L. SCHMITT, Monnaies $X V$, p. 387. F. REINERT, "La numismatique celtique au Luxembourg...", p. 342. Esta serie constituye el 20,2\% del total de monedas recuperadas en este lugar (505 sobre 2492). Sobre las monedas halladas en este oppidum trevero, vid: L. REDING, Les monnaies gauloises de Tetelbierg, Luxembourg, 1972. G. DEPEYROT, Le numéraire celtique VII..., pp. 193-196 da el listado de hallazgos de esta moneda, pero incluye incomprensiblemente también las piezas de CARINA, a las que no da de forma independiente.

${ }^{23}$ El potin es una aleación de cobre, estaño y plomo (a veces con restos de otros metales), que fue utilizado por numerosas etnias de la Galia, principalmente en su área septentrional, para fabricar moneda fraccionaria, generalmente mediante el proceso de fundición.

${ }^{24}$ A su vez, su anverso deriva de otra emisión romana, un sestercio (RRC 455/5) del año 45 a.C.

25 A. BLANCHET, Traité des monnaies..., p. 389. VIAN, "La trouvaille d'HusignyGodbrange", p. 196.

${ }^{26}$ S, SCHEERS, Les monnaies de la Gaule..., p. 72; Traité de numismatique celtique..., p. 768. L.-P. DELESTRÉE y M. TACHE, Nouvel Atlas..., p. 63. J.-B. COLBERT DE BEAULIEU, "Notules de Numismatique Celtique II", Ogam, 3 (1954), 91-94, pp. 93-94. S. SCHEERS, Les 
La segunda imitación fue efectuada a nombre de C. Carrinas (cos. suff. 43 a.C.) (RPC 502. Sear 474. Scheers 162 clase II) ${ }^{27}$, de 15/16 mm de diámetro, y de un peso medio de $2.90 \mathrm{~g}$. (9 ejemplares) ${ }^{28}$. Su tipología es semejante a la acuñación de Hircio, aunque más grosera y torpe ${ }^{29}$, y la leyenda refleja, lógicamente, en vez de A. HIRTIVS, CARINA ${ }^{30}$, en escritura retrógrada, es decir, SARINAC ${ }^{31}$.
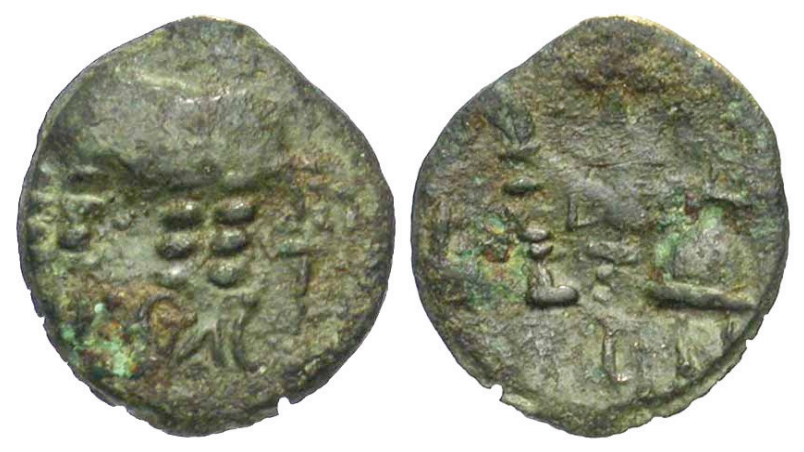

Esta emisión se acuñó también entre los Treveri $^{32}$, en el mismo oppidum de Tetelbierg, donde se han encontrado nueve de los diez especimenes conocidos

monnaies de la Gaule..., pp. 74 y 176; Traité de numismatique celtique..., p. 748. S. GOUET, M. PRIEUR y L. SCHMITT, Monnaies XV, p. 430 señalan que el reverso de una de las monedas de potin más extendidas, la del «personaje corriente» (BN 8124-8132. DT 155. LT 8124), sería una imitación gala de RRC 443/1, en la que figuraría un paquidermo. En realidad, L.-P. DELESTRÉE y M. TACHE, Nouvel Atlas..., p. 52 consideran que esta amonedación de los Remi podía haberse producido desde finales del s. II a.C., siendo el animal representado irreconocible, por lo que no tiene nada que ver con la presente cuestión.

${ }^{27}$ A. BLANCHET, Traité des monnaies..., p. 356. S. SCHEERS, Les monnaies de la Gaule.., p. 72. K. GRUEL, La monnaie chez les gaulois, p. 79. M. MAYS, Catalogue of the Celtic Coins.., p. 37. R. S. SEAR, The History and Coinage..., p. 474.

${ }^{28}$ L.-P. DELESTRÉE y M. TACHE, Nouvel Atlas..., p. 120, como anteriormente hemos comentado con Depeyrot, de manera incomprensible, incluyen las acuñaciones de HIRTIVS y CARINA en un mismo grupo (DT 612), con una media de $2.74 \mathrm{~g}$. y $16 \mathrm{~mm}$. de diámetro. Probst, Catalogue illustré..., p. 82 da como peso (medio) 3.79 g, ciertamente elevado, como en el caso de HIRTIVS.

${ }^{29}$ A. BLANCHET, Traité des monnaies..., p. 356. S. SCHEERS, Les monnaies de la Gaule..., pp. 71-72 y 173 .

${ }^{30}$ Probst, Catalogue illustré..., p. 82 señala la existencia de una variante en la que figura una T delante del elefante.

${ }^{31}$ M. GRANT, From Imperium to Auctoritas..., p. 3 n. 4 señaló que el presente letrero era una mala realización del de A. HIRTIVS, pero su lectura está completamente asegurada.

${ }^{32}$ A. BLANCHET, Traité des monnaies..., p. 356; Manuel de numismatique française..., p. 59. V. TOURNEUR, "César, Hirtius...", p. 555. S. SCHEERS, "Le Tetelbierg et la circulation monétaire...", p. 227. R. WEILLER, "Les techniques de fabrication...", p. 627. L. REDING, "Die Treverermünzen im Raum...”, p. 323. K. GRUEL, La monnaie chez les gaulois, p. 79. A. M. BURNETT, M. AMANDRY y P. P. RIPOLLÈS, Roman Provincial Coinage..., pp. 147-148. MAYS, Catalogue of the Celtic Coins..., p. 37. J. METZLER, Das Treverische Oppidum..., p. 129. LEIDIG, “C. CARRINAS C.F....”, p. 214. L.-P. DELESTRÉE, "La romanisation et la fin du mon- 
hasta ahora ${ }^{33}$. Parece que se efectuó en un breve espacio de tiempo, al provenir todos los ejemplares del mismo cuño de anverso ${ }^{34}$.

\section{LOS BRONCES A NOMBRE DE ARDA}

Wightman responsabilizó al jefe trevero Arda de la emisión de ambas acuñaciones. Arda habría emitido en primer lugar estáteras de oro de baja calidad (BN 8817-8818. DT 601-602. LT 8817. RIG IV 36), efectuadas durante la Guerra de las Galias (58-51 a.C.) y, posteriormente, prosiguió sus emisiones en plata y bronce en gran cantidad siguiendo prototipos romanos (BN 8839-8858. DT 603611a. LT 8839,8849 y 8852 . RIG IV $37-43)^{35}$. Su ceca parece haber sido igualmente el oppidum de Titelberg, donde se han encontrado unas 800 de sus piezas ${ }^{36}$.

El hecho de que las emisiones de Arda se emitieran en Titelberg, y de que su amonedación en plata y bronce parece ser contemporánea a la efectuada por Hircio $^{37}$, hace difícil evitar pensar que existiera algún tipo de relación entre ambos personajes (quizás Hircio fuera el responsable de la obediencia de Arda a Roma),

nayage...", p. 29; "La romanisation et la fin du monnayage...”, p. 136. L.-P. DELESTRÉE y M. TACHE, Nouvel Atlas..., p. 120. G. DEPEYROT, Le numéraire celtique VII..., p. 141. J. VAN HEESCH, "Les Romains et la monnaies gauloise...", p. 240. R. H. M. LOSCHEIDER, "Militär und Romanisierung...”, p. 109. J. B. COLBERT DE BEAULIEU, Traité de numismatique celti$q u e . .$, p. 36 indica únicamente que proviene del norte de la Galia.

${ }^{33}$ E. M. WIGHTMAN, "Military arrangements...", p. 121. S. SCHEERS, "Le Tetelbierg et la circulation monétaire...", p. 227. R. WEILLER, "Les techniques de fabrication...", p. 627. GRUEL, La monnaie chez les gaulois, pp. 89, 79. A. M. BURNETT, M. AMANDRY y P. P. RIPOLLÈS, Roman Provincial Coinage..., p. 148. MAYS, Catalogue of the Celtic Coins..., pp. 37 y 66. J. METZLER, Das Treverische Oppidum..., p. 162. R. PROBST, Catalogue illustré..., p. 82. R. S. SEAR, The History and Coinage..., p. 271. C. HASELGROVE, "The Development of Iron Age Coinage...", p. 160. LOSCHEIDER, "Militär und Romanisierung...", p. 113. J. VAN HEESCH, "Les Romains et la monnaies gauloise...", p. 240. S. SCHEERS, "Le Tetelbierg et la circulation monétaire..”, p. 79, 227 señala que las monedas de HIRTIVS y CARINA representan el $20.61 \%$ del total encontrado en este oppidum, que significan el $86.97 \%$ de las piezas con origen conocido. Ambas amonedaciones se encuentran en segundo lugar en el conjunto de monedas encontradas en Titelberg.

${ }^{34}$ A. M. BURNETT, M. AMANDRY y P. P. RIPOLLÈS, Roman Provincial Coinage..., p. 148.

${ }^{35}$ Vid: L. REDING, "Le bronze ARDA aux globules BN 8841", en Mélanges offerts au Dr. J.-B. Colbert de Beaulieu, Paris, 1987, 709-721. Por el contrario, L.-P. DELESTRÉE y M. TACHE, Nouvel Atlas..., p. 119 y G. DEPEYROT, Le numéraire celtique VII..., pp. 139 y 170, consideran que las monedas de oro serían posteriores a la Guerra de las Galias.

${ }^{36}$ S. SCHEERS, Traité de numismatique celtique..., p. 150. E. M. WIGHTMAN, "Military arrangements...”, pp. 121-122.

${ }^{37}$ P-C. VIAN, "La trouvaille d'Husigny-Godbrange", p. 198. E. M. WIGHTMAN, "Military arrangements...”, p. 122. 
por lo que se ha considerado que Arda fuera el encargado de la emisión del bronce de Hircio $^{38}$.

Scheers rechaza la hipótesis de Wightman, debido a que los bronces de Arda e Hircio no se suceden metrológicamente: las monedas de Arda pierden peso hacia el fin de su numerario, mientras que las de Hircio mantienen un peso elevado relativo $)^{39}$.

De hecho, Scheers considera que los bronces de Hircio (y de Carrinas) parecen suceder y reemplazar las monedas de Arda a partir del año 45 a.C. ${ }^{40}$ Ha de señalarse que, como en Noricum y en Boiohaemum, en Belgium un mismo taller acuñaba monedas para distintas etnias o divisiones de éstas: en este caso, Titelberg, acuñó tanto las piezas a nombre de Arda como las de Hircio y Carrinas, monedas de plata con personaje sentado (BN 9378-9387. DT 201-202. LT 9383) ${ }^{41}$, potines con jabalíes (BN 8445-8448. DT 222. LT 8445) y con animales enfrentados (BN 7459 y 7465-7466. DT 224. LT 7465), e incluso unos potines tardíos (BN 8133. DT 223. LT 8133) ${ }^{42}$. Esta interpretación ha sido rechazada recientemente por Haselgrove, que considera que alguno de los tipos de Arda son posteriores a las monedas a nombre de Hircio, a partir de los recientes hallazgos en Titelberg $^{43}$.

Ha de tenerse en cuenta que, después de las Guerras de las Galias, todavía se acuñó moneda de oro y plata por parte de los Galos ahora sometidos a los Romanos, aunque fue concluyéndose paulatinamente, lo que originó a su vez la acu-

${ }^{38}$ E. M. WIGHTMAN, "Military arrangements...", p. 122. A Arda se le habían atribuido también unos potines (BN 7467-7470. DT 210. LT 7467) que, por su distribución, parecen haber sido acuñados por los Bellovaci, pero cuya clase III parecen haber sido efectuados por los Suessiones. Vid: J. DESBORD, "L'atelier monétaire gaulois de Villeneuve-Saint-Germain (Aisne) et sa production”, $R N 31$ (1989), 7-24. En realidad, el letrero ha de ser leído como АГН $\Delta$ (RIG IV 14), lo que explica su origen no trevero, sino suesson.

${ }^{39}$ S. SCHEERS, "Le Tetelbierg et la circulation monétaire...", p. 227 n. 15. S. SCHEERS, Traité de numismatique celtique..., p. 208 había pensado previamente que las monedas de ARDA y las de A. HIRTIVS podían proceder de talleres diferentes, debido a que las últimas emisiones de ARDA pesan entre 2.50 y $0.90 \mathrm{~g}$, mientras que las de A. HIRTIVS son más pesadas.

40 S. SCHEERS, Traité de numismatique celtique..., p. 208; "Le Tetelbierg et la circulation monétaire...”, p. 227. Pero S. SCHEERS, Traité de numismatique celtique..., p. 666 la fecha entre los años 58 y $49 / 48$ a.C.

${ }^{41}$ A excepción de esta serie, el resto se emitió después de la conquista de las Galias por César.

42 S. SCHEERS, Traité de numismatique celtique..., p. 186; "Le Tetelbierg et la circulation monétaire...”, pp. 227 y 230.

${ }^{43}$ C. HASELGROVE, “The Development of Iron Age Coinage..”, p. 152; “Archeological dating of Iron Age Coinage in northern France", en XII. Internationaler Numismatischer Kongress Berlin 1997. Akten, I, Berlin, 2000, 401-417, p. 414. 
ñación de grandes cantidades de bronce ${ }^{44}$; las primeras emisiones de este último metal por parte de los Treveros comenzó a principios de la década de los años cuarenta, continuando en la siguiente década ${ }^{45}$.

Si bien en un principio se había considerado que el cambio a emisiones de bronce se debía a la prohibición por parte de Roma de acuñar metales preciosos después de la conquista, esta consecuencia no fue debido a factores políticos, sino que más bien fue causado por el agotamiento de los metales preciosos durante la Guerra de las Galias, que forzó a las elites a buscar nuevos recursos para financiar sus séquitos ${ }^{46}$.

Todo ello parece quedar corroborado por el hecho de que no se constata evidencia de intervención política romana a otros niveles desde el punto de vista monetario. No sólo la moneda romana no penetró en el área, sino que tampoco tuvo efectos en el sistema metrológico, ya que los bronces treveros, como los que presentamos, no tienen relación con el as romano ${ }^{47}$.

La extraordinaria abundancia de la emisión de HIRTIVS, con numerosos ejemplares con leyenda retrógrada o deformada o, simplemente, sin leyenda, parece indicar que se emitió durante varios años, hasta enlazar con la de CARINAS (ca. 30 a.C.), que es su clara continuación ${ }^{48}$.

${ }^{44}$ C. HASELGROVE, "The Development of Iron Age Coinage...”, p. 149; "The incidence of Iron Age coins...”, p. 283 (quien indica además que el bronce sustituyó al potín). D. G. WIGG, "The development of the monetary economy...", p. 107. L.-P. DELESTRÉE, "La romanisation et la fin du monnayage...”, p. 133. J. VAN HEESCH, "Les Romains et la monnaies gauloise..”, pp. 236-237.

${ }^{45}$ D. G. WIGG, "The development of the monetary economy...,", p. 107.

${ }^{46}$ D. G. WIGG, "The development of the monetary economy...,", p. 107, cf. p. 120.

${ }^{47}$ D. G. WIGG, "The development of the monetary economy...", p. 108. L.-P. DELESTRÉE, "La romanisation et la fin du monnayage..", p. 133.

${ }^{48}$ S. SCHEERS, Les monnaies de la Gaule..., p. 172; "L'histoire monétaire de la Gaule Belgique..", p. 199; Traité de numismatique celtique..., pp. 152 y 191; "Le Tetelbierg et la circulation monétaire...", p. 227; "Géographie et chronologie des monnaies...”, p. 77. E. M. WIGHTMAN, "Military arrangements...", p. 120 n. 64. H. M. CRAWFORD, Coinage \& Money under the Roman Republic, p. 218. GRUEL, La monnaie chez les gaulois, p. 79. A. M. BURNETT, M. AMANDRY y P. P. RIPOLLÈS, Roman Provincial Coinage..., pp. 147-148. C. HASELGROVE, “Archaeological Evidence for the dating of Iron Age Potin Coinage: the Case of Scheers 191", en Actes du XIe Congrès International de Numismatique, II, Louvain-la-Neuve, 1993, 11-20, p. 15. M. MAYS, Catalogue of the Celtic Coins..., pp. 37 y 66. PROBST, Catalogue illustré..., p. 82. C. BRENOT Y S. SCHEERS, Catalogue des monnaies..., p. 140. G. DEPEYROT, Le numéraire celtique VII..., pp. 141 y 193. 


\section{OTROS BRONCES GALOS A NOMBRE DE HIRCIO}

Más complicado es decidir qué cronología tiene la acuñación RPC 501, que deriva directamente de la problemática planteada por la fecha de emisión del denario de César. Como Hircio obtuvo la aclamación como imperator en los años 45/44 a.C., en principio, cabría pensar que esta emisión se habría emitido antes de esta fecha, pues la omisión de este título contrasta con la acuñación RPC 503, en la que sí figura ${ }^{49}$.

Así, se conoce una breve emisión de bronces en las que figura la leyenda A.HIR.IMP., en cuyo reverso figuran los nombres de varios jefes galos (BN 7359 y 8086-8094. DT 675-679. LT 8086, 8092 y 8094. RPC 503. Depeyrot, V, 164167. Scheers 153. Sear $475-478)^{50}$, de $14 \mathrm{~mm}$. de diámetro y un peso medio de 2.60 g. ${ }^{51}$, que varía entre 1.70 y 3.25 g. ${ }^{52}$ Esta serie presenta tres variantes ${ }^{53}$ :
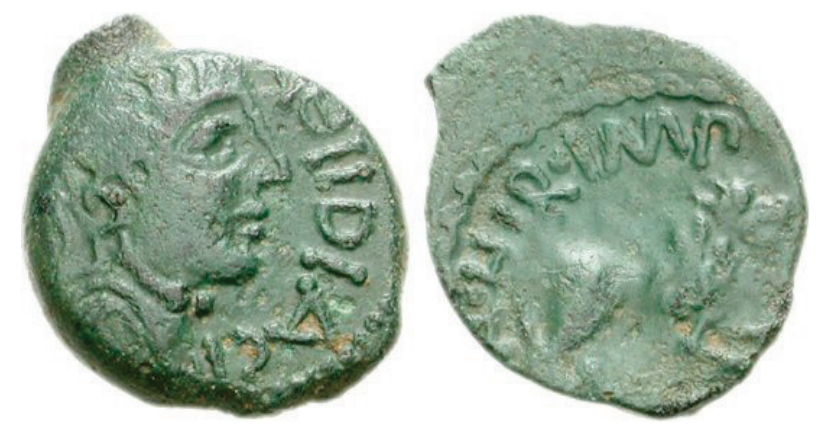

-Clase I (BN 7359 y 8086-8091. DT 675-676. LT 8086. Depeyrot, V, $164)^{54}$ : cabeza humana estilizada a dra., con torques en el cuello ${ }^{55}$; alrede-

49 A. M. BURNETT, M. AMANDRY y P. P. RIPOLLÈS, Roman Provincial Coinage..., p. 148. L.-P. DELESTRÉE y M. TACHE, Nouvel Atlas..., p. 132.

${ }^{50}$ Como indica B. FISCHER, "Celticité et romanisation des légendes monétaires gauloises", en Die Kelten und Rom: Neue numismatische Forschungen - Les Celtes et Rome: Nouvelles etudes numismatiques, Mainz am Rhein, 2005, 59-70, p. 68, a pesar de la mención de Hircio, se trata de monedas galas, tanto por su tipología como por los nombres del anverso.

51 A. M. BURNETT, M. AMANDRY y P. P. RIPOLLĖS, Roman Provincial Coinage..., p. 148. G. DEPEYROT, Le numéraire celtique $V$. Le centre parisien, Wetteren, 2005, pp. 158-159 da un peso medio de $3,00 \mathrm{~g}$.

${ }^{52}$ L.-P. DELESTRÉE y M. TACHE, Nouvel Atlas..., p. 132 ofrecen los siguientes datos: DT $675,2.53$ g. de peso y $14 \mathrm{~mm}$. de diámetro, DT 676, $3.01 \mathrm{~g}$. y $14 \mathrm{~mm}$. respectivamente; DT 677, 2.70 g. y 15 mm.; DT 678, 2.63 g. y 15 mm.; DT 679, 2.26 g. y $14 \mathrm{~mm}$.

53 S. SCHEERS, Les monnaies de la Gaule..., p. 169; Traité de numismatique celtique..., p. 648. A. M. BURNETT, M. AMANDRY y P. P. RIPOLLÈS, Roman Provincial Coinage..., p. 148.

${ }^{54}$ S. SCHEERS, "Géographie et chronologie des monnaies...", p. 77 señala que las cabezas del anverso de estas monedas son de inspiración romana, pero se desconoce en que prototipos se basaron. 


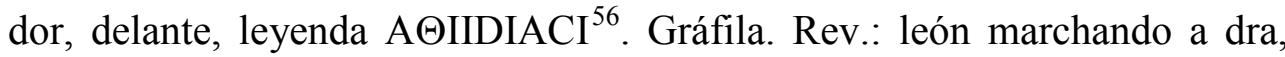
con la cola entre las patas; encima, leyenda A. HIR. IMP. Gráfila ${ }^{57}$.

-Clase II (BN 8092. DT 677. LT 8092. Depeyrot, V, 166): Anv.: cabeza humana estilizada a dra., con un collar o torques; alrededor, de izq. a dra., leyenda INIICRITVRIX ${ }^{58}$. Rev.: león a dra.; encima, leyenda A. HIR. $\mathrm{IMP}^{59}$.

-Clase III (BN 8093-8094. DT 678-679. LT 8094. Depeyrot, V, 165 y 167) ${ }^{60}$ : Anv.: cabeza humana barbada a dra., con cabellera estilizada en tres bandas; alrededor, leyenda CORIARCO[?] $\mathrm{CA}^{61}$, más otros signos indistinguibles $^{62}$. Rev.: león a dra. sobre una línea de suelo; encima, leyenda [A. HIR.] $\mathrm{IMP}^{63}$.

Según Scheers, el tipo del león se encuentra frecuentemente en las amonedaciones de la Galia del s. I a.C., entre los Suessiones ${ }^{64}$, los Veliocasses, los Au-

${ }^{55}$ G. DEPEYROT, Le numéraire celtique $V . . .$, p. 158 considera que se trata de un busto de mujer.

${ }^{56}$ Se han señalado diferentes lecturas a esta leyenda (RIG IV 13: su tipología y su epigrafía son célticas), como, p.e., ATIIDIACI, por parte de Depeyrot, que debería resolverse como At(h)eidiaci. F. DE SAULCY, "Lettres à M. A. de Longpérieur sur la numismatique gauloise. I", $R N$ (1858), 437-466, p. 444 considera que este personaje puede identificarse con Atisios, lo que S. SCHEERS, Les monnaies de la Gaule..., p. 171; Traité de numismatique celtique..., pp. 142-143 acertadamente niega.

${ }^{57}$ G. DEPEYROT, Le numéraire celtique $V . . .$, p. 157 detalla el hallazgo de 21 piezas.

${ }^{58}$ RIG IV 187. Se ha de resolver Inecriturix

${ }^{59}$ G. DEPEYROT, Le numéraire celtique $V . . .$, p. 158 detalla el hallazgo de 10 piezas.

60 J.-B. COLBERT DE BEAULIEU y B. FISCHER, Recueil des Inscriptions Gauloises (R.I.G.), volume IV: les Légendes Monétaires, Paris, 1998, p. 206 señalan que la lectura del reverso no tiene porqué llevar el letrero A. HIRTIVS. Se trata de una suposición, como se manifiesta en L.-P. DELESTRÉE y M. TACHE, Nouvel Atlas..., p. 132, que señalan que la leyenda se encuentra fuera del flan, aunque no hay especial motivo para suponer que no fuera así, debido a la homogeneidad que presenta con las otras dos clases. Una clase IV (DT 679), cuya leyenda del anverso se interpreta como ]CARIVS[ o ]CARIOS[, no aparece en RIG, ni tan siquiera en los letreros suprimidos, mientras que L.-P. DELESTRÉE y M. TACHE, Nouvel Atlas..., p. 132 y G. DEPEYROT, Le numéraire celtique $V$..., p. 129 defienden su diferenciación de la clase III. Al parecer, puede tratarse de una mala lectura de la leyenda del anverso de la clase II, pues el número BN 8092 aparece indistintamente, según los investigadores, atribuido a una u otra clase. Delestrée y Tache advierten que la lectura del anverso de la clase I es la única cierta en este grupo de emisiones, mientras que Depeyrot considera que la única lectura problemática es la de la clase III.

${ }^{61}$ Nueva lectura (RIG IV 119).

${ }^{62}$ G. DEPEYROT, Le numéraire celtique $V . . .$, p. 159 considera que, tanto en la clase IV como en la II, detrás de la cabeza hay una enseña en forma de jabalí.

${ }^{63}$ G. DEPEYROT, Le numéraire celtique V..., p. 158 detalla el hallazgo de 7 piezas de la clase II y 4 de la clase IV.

${ }^{64}$ L.-P. DELESTRÉE, "La romanisation et la fin du monnayage...”, p. 29; "La romanisation et la fin du monnayage...", p. 135 atribuye los bronces de esta tipología a esta etnia. 
lerci Eburovices ${ }^{65}$, los Lexovii, los Carnutes o, más generalmente, en los Bel$g^{6} e^{66}$. Especialmente, estas monedas tienen una gran analogía con las bronces de ROVECA de los Meldi $^{67}$ (BN 7643-7659. DT 582-584. LT 7646 y 7658. RIG IV 241) y los de ATISIOS REMOS de los Remi (BN 8054-8083. DT 594-596. LT 8054 y 8082 . RIG IV 56) ${ }^{68}$.
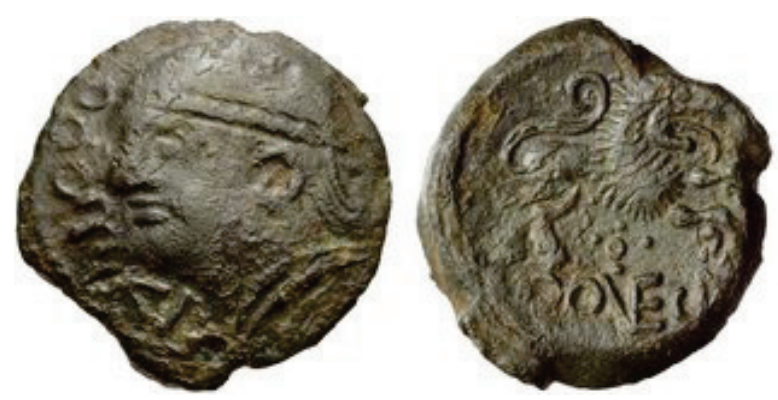

Bronce de Roveca (DT 583).

Ya Blanchet, creyendo erróneamente que estos bronces eran de los Remos, consideró que no se le podía imponer a un pueblo amigo el nombre del gobernador de la Galia. Pensaba que la aparición de estos nombres galos podían deberse a tres causas: los jefes querrían de esta forma manifestar su alianza a Roma; Hircio acuñó estas piezas bajo su propia autoridad, con el nombre de los jefes galos, en un gesto político fácil de comprender; o estos nombres galos serían magistrados monetales dependientes enteramente de Hircio ${ }^{69}$.

Debido al cursus honorum conocido de Hircio, parece que su mención como imperator debe fecharse en los años 45-44 a.C., por lo que estas piezas pueden pertenecer a esta fecha ${ }^{70}$. Scheers las fecha en el año 49 a.C., antes de que Hircio

${ }^{65}$ S. SCHEERS, "Géographie et chronologie des monnaies...”, p. 77 considera que uno de estos talleres se encontraría en este pueblo.

66 J.-B. COLBERT DE BEAULIEU, Traité de numismatique celtique..., p. 36. C. HASELGROVE, “The Development of Iron Age Coinage...”, p. 152 n. 186. Así: Meldi (BN 76437659. DT 582-584), Remi (BN 8054-8083. DT 594-596. LT 8054 y 8080), Veliocasses (BN 73577358. DT 649), Eburovices (BN 7105-7110), Lexovii (BN 7151-7155), Carnutes (BN 6361-6375).

${ }^{67}$ S. SCHEERS, Traité de numismatique celtique..., pp. 137 y 387. L.-P. DELESTRÉE y M. TACHE, Nouvel Atlas..., p. 385.

${ }^{68}$ S. SCHEERS, Les monnaies de la Gaule..., p. 170. L.-P. DELESTRÉE y M. TACHE, Nouvel Atlas..., p. 117. C. BRENOT y S. SCHEERS, Catalogue des monnaies..., p. 145 consideran que estos bronces no pueden localizarse con garantías.

${ }^{69}$ A. BLANCHET, Traité des monnaies..., p. 382.

${ }^{70}$ M. GRANT, From Imperium to Auctoritas..., p. 393. S. SCHEERS, Traité de numismatique celtique..., pp. 143 y 191; "Géographie et chronologie des monnaies ...", p. 77. E. M. WIGHTMAN, "Military arrangements...", p. 121. A. M. BURNETT, M. AMANDRY y P. P. RIPOLLÈS, Roman Provincial Coinage..., p. 148. C. HASELGROVE, "The Development of Iron 
se trasladara fuera de la Galia ${ }^{71}$. Babelon consideró que estas piezas se efectuarían junto con las imitaciones del denario de César, es decir, a partir del año 58 a.C. ${ }^{72}$

Otros investigadores señalan que Hircio poseyó el imperium de las ciudades belgas entre los años 44 y 31 a.C. ${ }^{73}$. Pero esto es imposible, pues murió en el campo de batalla en el año 43 a.C. durante la guerra de Mutina, y es una evidente confusión con la posible cronología de emisión RPC 501.

Si bien se ha atribuido la serie RPC 503 al pueblo de los $R e m i^{74}$, esto no parece ser cierto, pues su área de distribución de los hallazgos se encuentra entre los ríos Sena y Loira (es decir, fuera de Belgica $^{75}$ ), y no se documenta ningún hallazgo en el territorio de esta etnia ${ }^{76}$. Recientemente, estas emisiones se han atribuido a diversos pagi de la región parisina ${ }^{77}$, aunque más bien parecen pertenecer a los Aulerci Eburovices ${ }^{78}$.

Se desconoce la causa por la que Hircio obtuvo la aclamación como impera$t r^{79}$, por lo que Tourneur la pone en duda y la considera una confusión de los

Age Coinage...", p. 152. WIGG, “The development of the monetary economy...”, p. 108. G. DEPEYROT, Le numéraire celtique $V$..., pp. 158-159, los fecha ca. 50-30 a.C., seguramente debido a la longevidad del bronce de Hircio propiamente dicho.

${ }^{71}$ S. SCHEERS, Les monnaies de la Gaule..., p. 172. M. H. CRAWFORD, Coinage \& Money under the Roman Republic, p. 218. C. BRENOT y S. SCHEERS, Catalogue des monnaies..., p. 140. H. A. GRUEBER, Coins of the Roman Republic..., p. 526 duda entre estas dos fechas pero finalmente se pronuncia por la más antigua, ya que considera que su tipología no habría sido revivida después de la muerte de César (44 a.C.).

72 E. BABELON, Description historique..., p. 542. H. A. GRUEBER, Coins of the Roman Republic..., p. 526 rechaza esta fecha como inadmisible.

${ }^{73}$ S. SCHEERS, Les monnaies de la Gaule..., p. 173; Traité de numismatique celtique..., pp. 190. J.-B. COLBERT DE BEAULIEU y B. FISCHER, Recueil des Inscriptions Gauloises..., pp. 60 y 302 .

${ }^{74}$ L. MAXE-WERLY, "État actuel de la numismatique rémoire", pp. 435-440. A. BLANCHET, Traité des monnaies..., pp. 173 y 382-383. A. BELTRÁN MARTÍNEZ, Introducción a la Numismática Universal, Madrid, 1987, p. 15. M. GRANT, From Imperium to Auctoritas..., p. 393. S. SCHEERS, Les monnaies de la Gaule..., p. 171. E. M. WIGHTMAN, "Military arrangements...", p. 121 debido al parecido estilístico con las monedas de ATISIOS REMOS. S. SCHEERS, Un complement a l'Atlas des monnaies gauloises de Henri de la Tour, Paris, 1992, p. 26 los menciona en interrogante. Esta teoría se basa en que la residencia de los prefectos romanos era Durocortorum (Reims) (Str. 4, 3, 5).

${ }^{75}$ S. SCHEERS, Traité de numismatique celtique..., p. 190.

${ }^{76}$ S. SCHEERS, Les monnaies de la Gaule..., p. 170; Traité de numismatique celtique..., pp. 142 y 649. A. M. BURNETT, M. AMANDRY y P. P. RIPOLLÈS, Roman Provincial Coinage..., p. 148 .

${ }^{77}$ L.-P. DELESTRÉE y M. TACHE, Nouvel Atlas..., p. 132.

${ }^{78}$ G. DEPEYROT, Le numéraire celtique V..., pp. 128-129 y 158-159, con mapa de distribución.

79 E. M. WIGHTMAN, "Military arrangements...”, p. 121. J. METZLER, Das Treverische Oppidum.., p. 130. J. VAN HEESCH, "Les Romains et la monnaies gauloise...", p. 240 consideran que Hircio estuvo activo contra ciertas etnias transrenanas. En realidad, lo único que se conoce es que un delegado suyo, Aurelio, estuvo en tratos con los Germanos y otros pueblos de la zona (Cic. 
jefes galos ${ }^{80}$. No parece que Hircio impusiera una amonedación con su nombre. Posiblemente se quisiera reconocer con esta acción el dominio de Roma, quizás en un momento en que existieron ciertas tensiones en el territorio donde se acuñaron.

\section{PROBLEMAS DE CRONOLOGÍA.}

Al estar presente Hircio en la Galia durante los años $54-52$ y $51-50$ a.C. ${ }^{81}$, los editores de RPC consideran que la emisión RPC 501 sería acuñada en este último periodo, y adoptan la cronología defendida por Sydenham para el denario, quien lo había datado $c a$. el año 50 a.C. ${ }^{82}$ Babelon lo había fechado en el año 58 a.C. ${ }^{83}$, mientras que Nash $c a$. el año 48 a.C. ${ }^{84}$

Otros investigadores prefieren el año 45/44 a.C. ${ }^{85}$, momento en que Hircio ocupó el cargo de propretor de las Galias Transalpina y Comata, en cuyo transcur-

Att. 14, 9, 3), tras conocerse el asesinato de César (idus de marzo del año 44 a.C.). De esta forma, C. HASELGROVE, "Culture process on the periphery: Belgic Gaul and Rome during the late Republic and early Empire", en Centre and Periphery in the Ancient World, Cambridge, 1987, 104-124, p. 114 no menciona nada al respecto cuando habla de las rebeliones y problemas fronterizos en la Gallia Bélgica tras la conquista y hasta Augusto. T. R. S. BROUGHTON, The Magistrates of the Roman Republic. Volume II. 99 B.C.-31 B.C., Atlanta, 1952 p. 311 opina que posiblemente Aurelio sería un legatus.

${ }^{80}$ V. TOURNEUR, “César, Hirtius...”, p. 557.

${ }^{81}$ G. V. SUMNER, “The Lex Annalis under Caesar”, Phoenix 25 (1971), 246-271 y 357-371, p. 256 señala que, por desgracia, su estatuto no está nada claro. BROUGHTON, The Magistrates of the Roman Republic..., p. 225 indica que quizás se trate de un legado.

${ }^{82}$ L. MAXE-WERLY, "État actuel de la numismatique rémoire", p. 345. E. SYDENHAM, Roman Republican Coinage, London, 1952, pp. LXVI y 167. GRANT, From Imperium to Auctoritas..., p. 3 n. 4. A. M. BURNETT, M. AMANDRY y P. P. RIPOLLÈS, Roman Provincial Coinage..., pp. 147-148. MAYS, Catalogue of the Celtic Coins..., pp. 37 y 66. Probst, Catalogue illustré..., p. 78. R. S. SEAR, The History and Coinage..., p. 271. G. DEPEYROT, Le numéraire celtique VII..., p. 193. B. FISCHER, “Celticité et romanisation...”, p. 68.

${ }^{83}$ E. BABELON, Description historique..., pp. 11 y 541.

${ }^{84}$ D. NASH, "Plus ça change...: currency in Central Gaul from Julius Caesar to Nero", en Scripta Nummaria Romana. Essays Presented to Humphrey Sutherland, London, 1978, 12-31, p. 22. R. WEILLER, "Les techniques de fabrication...", p. 626 no se decanta entre el año 49 o el año 45 a.C.

${ }^{85}$ M. DAYET, “Le denier de César au type de l'éléphant", en VIIe carnet de numismatique celtique, RAE 11 (1960), 42-47, p. 47. A. ALFÖLDI, "Der Erklärung des Namens «Caesar» in den Spätrömischen Kompendien", en Bonner Historia-Augusta Colloquium 1966-1967, Bonn, 1968, 9-18, p. 15. S. SCHEERS, "L'histoire monétaire de la Gaule Belgique...", p. 199; Traité de numismatique celtique..., pp. 152 y 190; "Le Tetelbierg et la circulation monétaire...", p. 227; Un complement a l'Atlas des monnaies gauloises..., p. 31; "Géographie et chronologie des monnaies...”, pp. 76-77. J.-B. COLBERT DE BEAULIEU, Traité de numismatique celtique..., pp. $36 \mathrm{y}$ 326 n. 645. L. REDING, "Die Treverermünzen im Raum...”, p. 325. K. GRUEL, La monnaie chez les gaulois, p. 79. J. METZLER, Das Treverische Oppidum..., p. 129, aunque en 130 y 146 señala que pudo ser tanto en el año 49 a.C. como en el año 45 a.C., pues a este autor lo que le interesa es 
so fue revestido con el título de imperator, como manifiesta la emisión RPC 503. Hircio aparece como gobernador, probablemente como procónsul, de la Galia, gracias a una carta de Cicerón fechada el 17 de abril del año 44 a.C. (Cic. Att., 14, 9, 3), y se supone que ocupó este puesto durante los años $45-44$ a.C. ${ }^{86}$

Como indica Leidig, la emisión RPC 501 podría haber comenzado a producirse antes de la proclamación de Hircio como imperator, durante su gobierno de la Galia en los años 45-44 a.C., pues difícilmente éste habría obtenido esta mención al entrar inmediatamente en su cargo. De igual modo, si la emisión fuera anterior, no aparecería mencionado Hircio, sino el procónsul, César, o uno de sus legados con mando militar (aunque esta circunstancia es inusual), pues Hircio fue de hecho una especie de jefe de cancillería y, por ello, difícilmente podría haber emitido moneda a su nombre ${ }^{87}$.

Wightman considera que la fecha propuesta por Crawford para el denario del elefante de César encaja con la historia de la Galia, por lo que las primeras emisiones de la serie RPC 501 podrían haber comenzado $c a$. el año 49 a.C. Esto significaría que Hircio permaneció en la Galia en ese año, y las monedas podían seguir la lustratio del ejército de César (Caes. BGall. 8, 52, 1) mientras que, en abril del año 49 a.C., Hircio estaba junto a César en dirección a Hispania (Cic. Att. $10,4,6)$. También pudiera acontecer que Hircio volviera a la Galia en un momento que las fuentes literarias no han conservado, o que el presente numerario fuese emitido en su posterior gobierno provincial, ya citado ${ }^{88}$.

Las emisiones podrían pertenecer al año 49 a.C., pero no se conoce razón alguna por la que Hircio permaneciera en la Galia en este momento. Sea como fuere, no tendría que ser mucho después de producirse la lustratio del ejército en esta región ${ }^{89}$.

el orden interno de las emisiones treviras, que no afecta sea cual fuere el año en cuestión. L.-P. DELESTRÉE, "La romanisation et la fin du monnayage...", p. 29; "La romanisation et la fin du monnayage...", p. 135. L.-P. DELESTRÉE y M. TACHE, Nouvel Atlas..., pp. 120 y 132. S. GOUET, M. PRIEUR y L. SCHMITT, Monnaies XV, pp. 387-388. WOYTEK, Arma et Nummi..., p. 124. R. H. M. LOSCHEIDER, "Militär und Romanisierung..", p. 118. F. REINERT, "La numismatique celtique au Luxembourg...", p. 338. S. GOUET ET ALII, Celtic I, p. 195. S. SCHEERS, Les monnaies de la Gaule..., pp. 169 y 172 había defendido previamente como fecha ca. el año 49 a.C. mientras que C. HASELGROVE, "Les potins au personage courant", Gallia, 52 (1995), 5159 , p. 54 indica que sus monedas son posteriores a la Guerra de las Galias y menciona el año 45 a.C. como proconsulado de Hircio.

${ }^{86}$ T. R. S. BROUGHTON, The Magistrates of the Roman Republic..., p. 309. Este investigador utiliza como soporte varias cartas de Cicerón en las que se nombra a Hircio durante el año 45 a.C., pero en ninguna de ellas aparece la menor alusión o indicio sobre su gobierno en la Galia.

${ }^{87}$ T. LEIDIG, “C. CARRINAS C.F....", p. 214.

${ }^{88}$ E. M. WIGHTMAN, "Military arrangements...", p. 120 n. 64.

${ }^{89}$ E. M. WIGHTMAN, "Military arrangements...”, p. 120. 
Asimismo, Carrinas fue procónsul de las Galias en los años 31/30-29 a.C., (Dio Cass. 51, 21-22), por lo que es bastante lógico que la emisión RPC 502 fuera realizada durante su gobierno ${ }^{90}$. Como ya se ha indicado, parece que la serie RPC 501 de Hircio tendría una larga vida, y enlazaría con la RPC 502 de Carrinas.

Carrinas y M. Nonio Galo ${ }^{91}$ condujeron campañas victoriosas en el Norte; el primero ca. el año 30 a.C. contra los Morini y otras etnias ${ }^{92}$, y expulsó a los Suevi que habían cruzado el río Rin (Dio Cass. 51, 21, 6); el segundo, contra los Treveri, quienes habían obtenido ayuda de los Germanos (mencionados con el nombre de “Celtas”), en el año 29 a.C. (Dio Cass. 51, 20, 5) ${ }^{93}$.

Pero, existen varios gobernadores entre Hircio y Carrinas, como L. Munancio Planco (cos. 42 a.C.) ${ }^{94}$, años 44-43 a.C.; Marco Antonio (cos. I 44 a.C.), años

${ }^{90}$ E. BABELON, Description historique..., p. 542. A. BLANCHET, Traité des monnaies..., p. 356. V. TOURNEUR, "La Belgique pendant l'occupation militaire romaine..”, p. 180; “César, Hirtius...”, p. 556. S. SCHEERS, Les monnaies de la Gaule..., pp. 72 y 173; "L'histoire monétaire de la Gaule Belgique...", p. 199; Traité de numismatique celtique..., p. 190; "Le Tetelbierg et la circulation monétaire...”, p. 227; "Géographie et chronologie des monnaies...”, p. 77. J.-B. COLBERT DE BEAULIEU, Traité de numismatique celtique..., p. 36. WEILLER, "Les techniques de fabrication...”, p. 627. A. M. BURNETT, M. AMANDRY y P. P. RIPOLLÈS, Roman Provincial Coinage..., pp. 147-148. METZLER, Das Treverische Oppidum..., p. 129. C. HASELGROVE, "The Development of Iron Age Coinage...”, p. 160. WOYTEK, Arma et Nummi..., p. 124. L.-P. DELESTRÉE, "La romanisation et la fin du monnayage..", p. 136. A. BLANCHET, Traité des monnaies..., p. 356 señala que Carrinas sucedería a Hircio como "propretor de la Gallia Bélgica", lo que no es posible porque, como ya hemos señalado, Hircio ya había muerto hacía más de diez años.

${ }^{91}$ S. LEWUILLON, "Histoire, société et luttes de classes en Gaule: une feodalité a la fin de la République au debut de l'Empire", $A N R W$ II 4 (1975), 425-483, p. 502 advierte que Nonio podía no ser el sucesor de Carrinas en el gobierno de la Gallia Comata, sino su lugarteniente. Nonio aparece mencionado con el título de imperator en un epígrafe de Aesernia (CIL IX 2642. ILS 895): C. NONIO C. F. M. N. IIIVIR / QVINQ. M. NONIVS GALLVS / IMP. VIIVIR EPVL. FILIVS / POSVIT. Pero no está claro si esta inscripción refleja el presente suceso.

${ }^{92}$ S. LEWUILLON, "Histoire, société et luttes de classes en Gaule...", p. 602 considera que podrían tratarse de pueblos vecinos de los Treveri, por no decir los mismos Treveri o, en fin, cualquier etnia vecina al río Rin.

${ }^{93}$ L. REDING, "Die Treverermünzen im Raum...", p. 325 señala que sería en este momento cuando se destruiría el oppidum de Titelberg, lo que significaría el fin de las emisiones treveras, aunque no de la circulación de éstas. En realidad, el sitio siguió habitado, como prueban por sí mismas las 117 monedas de GERMANVS INDVTILLI L. (DT 707. LT 9248. RPC 506), del $c a$. 10 a.C., halladas en el lugar, donde incluso se ha dicho que fueron acuñadas, aunque como indica P. BELIËN, "Authorized or tolerated? Some new perspectives on the Germanus Indutilli l. series", en Coinage in the Iron Age. Essays in honour of Simone Scheers, London, 2009, 53-64, p. 50, al parecer esta tardía amonedación fue realizada en varios lugares a la vez. En realidad, la importancia de Titelberg decayó cuando la capital de la etnia de los Treveros pasó a Augusta Treverorum, ca. 18/17 a.C., y aunque siguió habitado, Titelberg estaba abandonado a mediados del s. I d.C.

${ }^{94}$ Sobre Planco, vid: M. RAMBAUD, "L. Munatius Plancus, gouverneur de la Gaule, d'après la correspondance de Cicerón”, Cahiers d'Histoire, 3 (1958), 103-105. Con este personaje se relaciona una emisión de bronces (RPC 504-505. BN 4792-4797. RIG IV 191 y 209). Vid: M. LABROUSSE, “Monnaies gauloises d'Attalus", Pallas, 14 (1978), 97-105; "Bronzes rutènes d'Atta- 
43-42 a.C.; etc. Por tanto, pudiera considerarse que la amonedación de Carrinas perteneciese a una fecha anterior ${ }^{95}$ o, más probablemente, la emisión de Hircio continuó emitiéndose sin interferencias de los siguientes gobernadores hasta $\mathrm{Ca}$ rrinas.

Leidig, jugando con las fuentes literarias y con la carrera de Carrinas, considera que éste sería el gobernador temporal entre D. Junio Bruto Albino ( $p r .45$ a.C.) ${ }^{96}$ quien, como legatus de César, derrotó a los Bellovaci sublevados en el año 46 a.C. (Liv. Per. 114, 9), e Hircio ${ }^{97}$, es decir, antes que César lo nombrara gobernador de la Hispania Ulterior para continuar la guerra contra Sexto Pompeyo (App. BCiv. 4, 83-84) ${ }^{98}$. Se desconoce cuándo Bruto abandonó la Galia, pero se encontraba en otoño del año 45 a.C. en Roma (Plut. Ant. 11, 1) en calidad de pretor $^{99}$. Por tanto, la acuñación RPC 502 se habría efectuado a inicios o en primavera del año 45 a.C., siendo anterior a la RPC 501 de Hircio: los Treveros desconocerían el nombramiento de Hircio en substitución de Carrinas, y de aquí que se conserven pocos ejemplares del segundo, pues, inmediatamente, al conocer el cambio de gobernador, iniciaron las emisiones a nombre de Hircio ${ }^{100}$.

Leidig se apoya en los pocos ejemplares conocidos de la acuñación RPC 502, su buen arte (en contra del resto de investigadores), y la leyenda retrógrada que exhiben. De esta forma, se eliminaría la diferencia cronológica entre los entre las emisiones de Hircio y Carrinas que, en vez de cubrir un periodo comprendido entre los años 45 y 30/29 a.C., se reduciría únicamente a dos o tres años ${ }^{101}$. Ade-

lus", Revue du Rouergue, 142 (1982), 133-137. X. PERRIER, "Une monnaie d'Attalos, prince rutène du sud-Rouergue", Cahiers d'archéologie aveyronnaise, 13 (1999), 57-62; "Les Monnaies d'Attalus: données complémentaires", Cahiers d'archéologie aveyronnaise, 15 (2001), 87-90. S. SCHEERS, "Une imitation insolite: le bronze d'Attalos à l'aigle", RBN, 145 (1999), 195-198.

${ }^{95}$ Es difícil, por no decir imposible, el caso contrario, pues ya se ha indicado que Hircio falleció en el ejercicio del consulado durante el año 43 a.C. Cabe la posibilidad de que se tratara de otro personaje, por lo demás desconocido, con el mismo nombre

${ }^{96}$ T. R. S. BROUGHTON, The Magistrates of the Roman Republic..., pp. 281 y 291 considera que este personaje habría sucedido a César al frente de la Galia como legatus pro praetore, como establece Apiano (App. BCiv. 2, 48, cf. 2, 111).

${ }^{97}$ L. Munacio Planco (cos. I 42 a.C.), substituiría a Hircio, con ocasión de la preparación de la expedición de César a Oriente.

${ }^{98}$ Para su estancia en la Hispania Ulterior y su lucha contra Sexto Pompeyo, vid: L. AMELA VALVERDE, "Sexto Pompeyo en Hispania", FIl 12 (2000), 11-46. B. J. LOWE: "Sextus Pompeius and Spain: 46-44 BC", en Sextus Pompeius (London, 2002), 65-102.

${ }^{99}$ T. R. S. BROUGHTON, The Magistrates of the Roman Republic..., p. 307, debido a que fue procónsul de la Galia Cisalpina en el año 44 a.C.

${ }^{100}$ T. LEIDIG, “C. CARRINAS C.F....", p. 218. L.-P. DELESTRÉE, "La romanisation et la fin du monnayage...”, p. 29. L.-P. DELESTRÉE y M. TACHE, Nouvel Atlas..., p. 120.

${ }^{101}$ T. LEIDIG, “C. CARRINAS C.F....", pp. 215-216. 
más, ésta sería la causa de que no aparecieran monedas con el nombre de otros gobernadores de la Galia a imitación del denario del elefante de César.

El problema que plantea la solución de Leidig es que las piezas de Carrinas son, realmente, de mal arte, y no explica el extraordinario volumen de emisión de la acuñación RPC 501, así como sus variantes, que forzosamente ha de haberse producido durante varios años. Si bien es cierto que se desconoce en gran medida la sucesión de los gobernadores de la Galia, ello no es óbice para situar a Carrinas en el año 45 a.C. para, de esta forma, poder ubicar cronológicamente la emisión RPC 502, y ser la única prueba la propia acuñación ${ }^{102}$.

Por ello, es mejor considerar que en primer lugar se efectuó la emisión RPC 501, que explicaría su alto número de ejemplares por la prolongación en el tiempo de su fabricación ${ }^{103}$. Se desconoce cuál sería la razón para efectuar una emisión tan pequeña como es RPC $502^{104}$, sino es que es la continuación de la RPC 501, de la que no es más que una degeneración ${ }^{105}$.

El hecho de que los sucesores inmediatos de Hircio no emitieran moneda con esta tipología pudiera ser debido simplemente a simple inercia, que Carrinas quizás intentó corregir. El cese de estas emisiones pudiera estar relacionado con el posible posicionamiento de Titelberg en la revuelta trevera del año 29 a.C., y que como consecuencia se fundara Augusta Treverorum ${ }^{106}$. Weiller señala que, a partir de $c a .30$ a.C., la amonedación trevera disminuye de cara a la emisión masiva de ases de Nemausus (RIC 154-161. RPC 522-526) ${ }^{107}$.

\section{FUNCIÓN}

Posiblemente, las monedas de Hircio y de Carrinas servirían como pago a diversas unidades auxiliares militares galas (exactamente treviras) de las legiones romanas $^{108}$, o mejor en la caballería ${ }^{109}$, aunque fuera únicamente como moneda

\footnotetext{
${ }^{102}$ L. AMELA, "La emisión cesariana RRC 443/1 y sus imitaciones”, p. 16.

${ }^{103}$ E. BABELON, Description historique..., p. 542. S. SCHEERS, "L'histoire monétaire de la Gaule Belgique...", p. 199.

${ }^{104}$ A. M. BURNETT, M. AMANDRY y P. P. RIPOLLÈS, Roman Provincial Coinage..., p. 148. 190.

105 S. SCHEERS, Les monnaies de la Gaule..., p. 173; Traité de numismatique celtique..., p.

${ }^{106}$ L. AMELA, “La emisión cesariana RRC 443/1 y sus imitaciones”, p. 16.

${ }^{107}$ R. WEILLER, "Les techniques de fabrication...”, p. 630.

108 J. VAN HEESCH, "Les Romains et la monnaies gauloise...”, p. 240 considera que estas monedas serían acuñadas coincidiendo con la visita del gobernador correspondiente, pero que no explicaría la abundancia de las piezas a nombre de Hircio y que Carrinas utilizase la misma tipología que el anterior, a no ser que los usuarios de estas piezas estuviesen familiarizados con ellas.
} 
fraccionaria ${ }^{110}$; el propio oppidum de Titelberg tuvo una ocupación militar de au$x_{i l i a^{111}}$. Al parecer, en un principio, en la etapa de la postconquista, los auxiliares galos eran pagados con monedas de plata, pero, fácilmente, podían haber sido igualmente remunerados con monedas de bronce, como seria el presente caso ${ }^{112}$, a pesar de que se afirme que no existen evidencias suficientes ${ }^{113}$.

En este contexto, debe tenerse en cuenta la emisión de cuadrantes a nombre de Cn. Iuli(us) L. f(ilius) q(uaestor) (CNH Corduba 1), emitidos a favor de Q. Cecilio Metelo Pio (cos. 80 a.C.) durante la guerra sertoriana en Corduba, su cuartel general $^{114}$. Sea como fuere, hay que tener presente que, al menos, en Belgium, antes del reinado de Augusto, es rara la presencia de piezas romanas, por lo que los indígenas emitían numerario propio para paliar la escasez de moneda circulante ${ }^{115}$.

Pero, por los hallazgos, parece ser que la moneda trevera era la única unidad de cambio aceptada en el oppidum de Titelberg, y que su circulación se limitaba a este punto. Por ello, Reinert se pregunta, después de considerar la existencia de hechos militares, si estamos frente a una moneda de necesidad después de un sitio $^{116}$. No creemos que sea este el caso, debido a lo numeroso de las piezas conservadas, y quizás la cuestión sea de orden interno, que todavía no podemos identificar.

${ }^{109}$ R. H. M. LOSCHEIDER, "Militär und Romanisierung...”, pp. 123-124, que justificaría la elección de tipos "exóticos" para una elite militar a la que estaba destinada. F. REINERT, "La numismatique celtique au Luxembourg...", p. 338.

${ }^{110}$ L.-P. DELESTRÉE y M. TACHE, Nouvel Atlas..., p. 120, significativamente, ilustran, para la pieza DT 612, un ejemplar hallado en el campamento de auxilia pre-augústeo de LaChaussée-Tirancourt (dep. Somme)

${ }^{111}$ J. VAN HEESCH, "Les Romains et la monnaies gauloise...”, p. 235.

${ }^{112}$ E. M. WIGHTMAN, "Military arrangements...", p. 120.

${ }^{113}$ D. NASH, "Plus ça change...: currency in Central Gaul...", p. 21.

114 F. CHAVES TRISTÁN, "Los dos momentos de amonedación en la Corduba romana", CoA, 10 (1980-1981), 3-11, pp. 7-9; "Consideraciones sobre los tesorillos de monedas de bronce en Hispania. República e inicios del Imperio Romano. II”, ANum, 21-23 (1991-1993), 267-284, p. 273; “Amonedación de las cecas latinas de la Hispania Ulterior", en Historia monetaria de Hispania antigua, Madrid, 1998, 233-317, pp. 257 y 302. M. H. CRAWFORD, Coinage \& Money under the Roman Republic..., p. 347. La cronología no es aceptada por todos los investigadores. Por ejemplo, L. VILLARONGA, Corpvs Nvmmorvm Hispaniae..., p. 401. M. P. GARCÍABELLIDO Y C. BLÁZQUEZ, Diccionario de cecas y pueblos hispánicos, con una introducción a la numismática antigua de la Península Ibérica. Volumen II: Catálogo de cecas y pueblos, Madrid, 2002, p. 108 la fechan a mediados del s. II a.C. Vid: L. AMELA VALVERDE, "La ceca de Corduba en época republicana", en XII Congreso Nacional de Numismática, Madrid, 2006, 177193.

${ }^{115}$ L.-P. DELESTRÉE, “La romanisation et la fin du monnayage...”, p. 31.

${ }^{116}$ F. REINERT, “La numismatique celtique au Luxembourg...”, p. 342. 


\section{CONCLUSIÓN}

El presente estudio nos muestra las dificultades que encontramos al estudiar la numismática gala, en este caso concreto la moneda de la post-conquista. Tanto la emisión RPC 501 de Hircio como la RPC 502 de Carrinas, copias del conocido denario RRC 443/1, efectuado por César, son acuñaciones de bronce efectuadas en la Galia, más específicamente en el oppidum de Titelberg, en territorio de la etnia de los Treveros.

La moneda RPC 501 habría comenzado a acuñarse $c a$. el año 45/44 a.C., y habría seguido siendo acuñada hasta que Carrinas fue gobernador de las Galias $c a$. 30 a.C., en que cambió su nombre por el de Hircio. Esta larga perduración no tendría nada de particular: piénsese, p. e., en la larga perduración de los alejandros y los lísimacos, monedas que debían su nombre a Alejandro III el Grande de Macedonia (336-323 a.C.) y a Lisímaco de Tracia (306-281 a.C.), y que se continuaron acuñando hasta inicios del s. I a.C., ya que su tipología daba seguridad a los usuarios de estas piezas. Quizás la larga perduración de las piezas RPC 501 a nombre de Hircio se debiera al mismo motivo: la mención de este personaje aseguraría la aceptación de esta moneda, cuya función principal sería la de pagar a los auxilia galos de los ejércitos romanos. 